УдК 331.005.95/96

\title{
УПРАВЛІННЯ ПРОЦЕСОМ ФОРМУВАННЯ КОМУНІКАТИВНОЮ КОМПЕТЕНЦІЄЮ СЕРЕДНЬОГО МЕДИЧНОГО ПЕРСОНАЛУ
}

\section{MANAGEMENT OF THE PROCESS OF FORMATION OF COMMUNICATIVE COMPETENCE OF NURSING PERSONNEL}

\author{
Стрюков Василь Васильович \\ аспірант, \\ Дніпровський національний університет імені Олеся Гончара \\ ORCID: https://orcid.org/0000-0002-5463-3124 \\ Striukov Vasyl \\ Oles Honchar Dnipro National University
}

\begin{abstract}
У статті розглядається комунікативна компетенція середнього медичного персоналу як ключова в структурі професійності медичної сестри. Показано зв'язок та вплив цієї компетенції на іншими. Описані етапи процесу формування та доказана необхідність постійного удосконалення. Аналізується вплив знань, умінь та навичок професійної комунікації на підвищення якості медичного обслуговування. Автор приходить до висновку о необхідності комунікативній підготовки медичних сестер з урахуванням місця роботи - клінічного профрілю відділення лікарні, а також автор доводить про необхідність оцінювання ссрормованої компетенції при прийомі на роботу молодого спеціаліста без професійного стажу. Окремо автор описує етапи управління процесом фрормування компетенції та зазначає функції управління на кожному етапі.

Ключові слова: комунікативна компетенція, медична сестра, управління, безперервне навчання, охорона здоров'я.

В статье рассматривается коммуникативная компетенция среднего медицинского персонала как ключевая в структуре профессионализма медицинской сестры. Показана связь и влияние этой компетенции на другие. Описаны этапы процесса формирования и доказана необходимость постоянного совершенствования. Анализируется влияние знаний, умений и навыков профессиональной коммуникации на повышение качества медицинского обслуживания. Автор приходит к выводу о необходимости коммуникативной подготовки медицинских сестер с учетом места работы - клинического профиля отделения больницы, а так же автор доказывает необходимость оценки сформированной компетенции при приеме на работу молодого специалиста без профессионального стажа. Отдельно автор описывает этапы управления процессом формирования компетенции и отмечает функции управления на каждом этапе.
\end{abstract}

Ключевые слова: коммуникативная компетенция, медицинская сестра, управление, непрерывное обучение, здравоохранение.

The article considers the communication process as a necessary condition for the development and functioning of all social systems, which is a tool for building both a separate social sphere and civil society in the state. The review of scientific sources allowed to generalize and determine the place of this competence in the structure of professionalism of nurses as a key competence. The author also describes the stages of management of the process of competence formation (college education - formation and consolidation; professional activity / lifelong learning improvement) and notes the management functions at each stage. Emphasizing that the main functions of management, in this case, are the provision of methodological material, evaluation of results, adjustment of knowledge and skills. Descriptive stages of management in the formation of competence were highlighted the relationship and impact on other competencies. The author concludes that the need for communicative training of medical college students in the mandatory testing during the internship and, if necessary, to adjust their knowledge, which allows to consolidate the acquired knowledge. Such an assessment is especially emphasized about the need to assess the formed competence when hiring a young specialist without professional experience, and if necessary to adjust skills taking into account the direction of the nurse's work, it is possible to prevent possible conflict situations between employees and patients. The author concludes that the possession of communication skills increases the motivation 
of self-development, increases work efficiency, reduces the risk of burnout. The main conclusion of the author is that in the period of medical reforms, rapid growth of private medicine the quality of medical care directly depends on the degree of formation of communicative competence and successful management of this competence, which, in turn, becomes the key to economic growth. Given the constant changes in the socio-economic environment, promising research in this direction is to look for methods of managing the process of forming the competence of nurses at different levels from hospital administration to the state level.

Keywords: communicative competence, nurse, management, lifelong learning, health care.

Постановка проблеми. Всі ми, ще 3 дитинства, знаємо, що «слово лікує», «слово ранить» та «слово може вбити». Слово несе певне значення, містить енергетику і неймовірно впливає на наш емоційний стан. Тому майже в усіх сорерах де робота пов'язана 3 людьми обслуговуючий персонал навчають мистецтву спілкування. Таким чином, слово в практиці молодшого медичного персоналу та медичної сестри має велике значення. Бо само вони є першими хто зустрічає пацієнтів і спілкування з ними відразу ж встановлює у нього почуття довіри або недовіри, приязні або неприязні, почуття перемоги над хворобою або приреченості. Медична сестра яка $€$ не тільки «посередником» між лікарем та пацієнтом, а $є$ активним учасником лікувального процесу обов'язково повинна володіти комунікативними навичками.

Зріст приватної медицини посилює тенденцію до бездоганності та відрегульованої комунікативної складової професійного рівня медичних працівників і як наслідок переосмислення комунікативної компетенції як одної 3 ключових, а володіння комунікативними вміннями та навичками, свідомо та розумно використовувані медичною сестрою - маркером якості медичного обслуговування, а значить необхідні нові та удосконалення старих механізмів управління процесом фоомування комунікативної компетенції $[1 ; 2]$.

Аналіз останніх досліджень. При вивченні робіт з теми дослідження статті показовим $€$ те, що за висвітлення цього питання беруться фрахівці різних профрілів - фрілософри, педагоги, лікарі, психологи, фрілологи, менеджери це свідчить про складність взаємовідносин між медичними працівниками і пацієнтом та високу потребу в наукових розробках вирішення проблем комунікативної компетенції медичного персоналу.

Зозуля А.І. [3] у своєму досліджені вивчав питання комунікації рідних та близьких з тяжкохворими при догляді за ними на дому та виявив залежність від спосібності рідних спілкуватися с хворим на їх якість життя. Горачук В.В. вивчала комунікативні питання як складову організації інфрормаційної підтримки прийняття управлінських рішень поліпшення якості медичної допомоги. Не дивлячись на високій рівень наукової розробки сам автор зазначає, що «їх результатів недостатньо для запровадження нових фрорм управління соціальними, організаційними, нормативно-правовими та економічними аспектами медичної допомоги 3 метою задоволення потреб пацієнтів» [4]. Загородній С.М. [5] відобразив функціонально-організаційну систему побудови суспільних комунікацій в окремій галузіохорона психічного здоров'я населення доказавши необхідність професійного спілкування з пацієнтами та профресійного спілкування між співробітниками при пацієнтах.

Золоторьова Ж.М. [6] запропонувала комплексну схему заходів протидії та подолання наслідків емоційного вигоряння медичних працівників які комунікують з інкрабельними хворими, але не було визначено форми та методи. Також було встановлено вплив соціально-економічних, - психологічних і поведінкових параметрів якості медичних працівників сорери паліативної допомоги на фрормування синдрому емоційного вигорання. Особливим компонентом в системі управління якістю медичної допомоги, з точки зору Яворського А.М., є проведення тренінгів, але в своєму досліджені присвяченому комунікативним навичкам медичного персоналу при роботі з пацієнтами не розкриває методологію проведення, фрорми комунікаційного впливу та засоби комунікації які можуть бути використані [7].

Вище перелічені роботи відображають проблематику комунікацій медичного персоналу з пацієнтом взагалі, не враховуючі особливостей спілкування в системах [8]:

- «молодшій медичний персонал - пацієнт»;

- «медична сестра - пацієнт»;

- «лікар - пацієнт»;

- «молодший медичний персонал - медична сестра - лікар».

Цими особливостями є: кількість та час спілкування з пацієнтом; рівень знань - розвинені навички; корпоративна та профресійна культура [9]. Тому, на наш погляд $€$ дуже цікавими наступні наукові роботи. Самбор- 
ська Н.М. у своїй дисертаційній роботі на звання кандидата педагогічних наук ретельно і чітко описує необхідність формування соціально - комунікативної компетенції у майбутніх фрахівців медсестринства, Характеризує гуманітарні дисципліни (основи фрілософрських знань, соціологія, українська мова за профресійним спрямовуванням, культурологія тощо) які переважно входять до циклу загальної підготовки, як дисципліни з дидактичним потенціалом щодо оволодіння нормами профресійної комунікації, упроваджено моделі та методики реалізації педагогічних умов формування соціально-комунікативної компетентності [10]. Хотілось би підкреслити, що ці дисципліни вивчаються студентами на першому курсі і входять до циклу загальної підготовки. На початку навчання студент має загальне уявлення про майбутню професію [11] і не в змозі до кінця оцінити змодельовану викладачем професійну ситуацію. Але, фрілософське відношення до життя, культура мовлення та поведінки, знання основ економіки та правознавства $€$ обов'язковими компонентами при орормуванні комунікативної компетентності. Доречно зауважити, що в навчальних планах для студентів медичних коледжів, які затверджені Міністерством охорони здоров'я, до циклу загальної підготовки включена дисципліна «Основи психології та між особове спілкування» на вивчення якої відводиться загальним обсягом 75 навчальних годин (12 теоретичних годин, 32 практичних години, 31 година для самостійного вивчення) або 2,5 ЕСTS. На післядипломному рівні навчання медичних сестер питання комунікаційної діяльності не визначені.

В монографії «Комунікації в охороні здоров'я» [12] колектив авторів досліджував фрункціонально-організаційну систему комунікацій та розробив модель взаємовідносин суб'єктів і об'єктів впливу системи комунікації. Була розроблена модель управління комунікаціями на рівні лікувально-профрілактичного закладу. Визначені компетенції з комунікації лікарів та медичних сестер (фрельдшерів), які набуються через проведення тренінгів та практичну діяльність на займаній посаді в лікувально-профрілактичному закладі під керівництвом головного лікаря, а методологію забезпечує ресурсний центр, який запропонували створити автори. Не дивлячись на ретельну роботу, автори монограсрії розглянули комунікативну компетенцію та управління процесом її фрормуванням у медичних сестер в загальному виді невраховуючі спе- цифріку роботи та стаж роботи середнього медичного персоналу.

Виділення невирішених раніше частин загальної проблеми. Аналіз наукових досліджень і джерел свідчить про недостатнє висвітлення питання, щодо оцінки комунікативної компетенції в структурі профресійності медичної сестри. Також, науковці не зосередили увагу на дослідженні практичних підходів до фрормування профресійного спілкування у молодих спеціалістів без робочого стажу.

Формулювання цілей статті (постановка завдання). Метою написання статті $€$ визначення ролі комунікативної компетентності в професійної діяльності медичної сестри. Освітити ступень розробленості методики викладання та методів управління процесом при фрормуванні компетентності.

Виклад основного матеріалу. Прагнення демократичного суспільства задовольнити найважливіші потреби сучасного людства, одна з них, це вчасне отримування об'єктивної, повної, достовірної та неупередженої інфрормації. Яка $є$ невід'ємною складовою процесу комунікації як між окремими індивідами так і цілими спільнотами, зі своїми особливостями та правовідносинами [13; 14]. Тому, комунікативна компетенція медичного персоналу, зокрема медичних сестер, в реаліях сучасної системи охорони здоров'я $\epsilon$ значимою, від якої може залежати результат лікування. Огляд останніх наукових публікації дозволяє нам розділити їх на три групи:

Перша група. Науковці свої роботи присвячують актуальності і необхідності спеціальної підготовки медичного персоналу комунікативним навичкам та її місце в структурі профресійності середнього медичного персоналу (рис. 1).

Як бачимо зі схеми профеесійність це сукупність компетентності: предметно-практична це сукупність знань з фундаментальних медичних наук без знань яких неможливо стати фрахівцем; профресійна комунікація здатність співробітника відчувати себе фрахівцем; пізнавальна це система вмінь до самостійної навчально-пізнавальної діяльності та самооцінки; управлінська здатність фрормування цілей та їх досягнення, аналізу результатів діяльності; правова знання нормативно - правової бази; інформаційна це здатність самостійно проводити пошук, аналіз, відбір, обробку та передачу необхідної інфрормації пацієнтам або колегам; особистісно-індивідуальна це ссрормовані уміння досягати поставленої мети при виконанні професійних завдань [16]. 


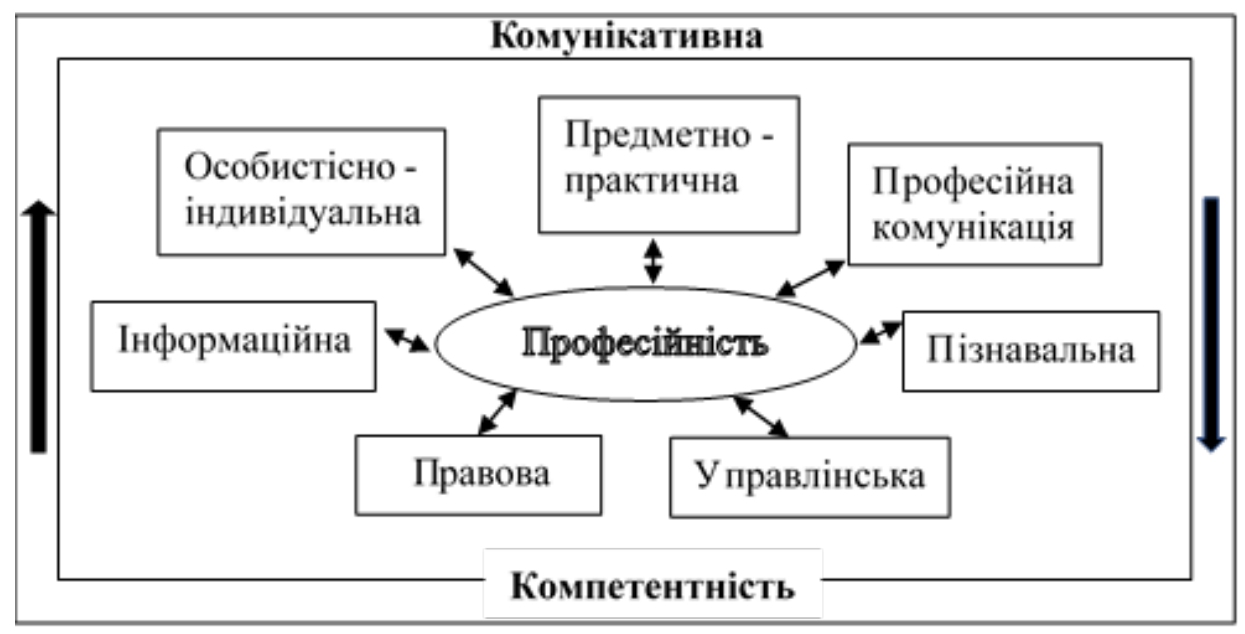

Рис. 1. Комунікативна компетентність В структурі професійності середнього медичного персоналу

Джерело: розроблено автором на підставі [9; 12; 15]

Комунікативна компетенція відіграє ключову роль та $€$ складним, системним елементом, вона пов'язує усі компетентності між собою та безпосередньо впливає на кожну 3 них окремо. Володіння навичками цієї компетентності допомагає розуміти себе, едективно взаємодіяти 3 оточенням (пацієнти, рідні пацієнтів, колеги) в умовах мінливого соціального середовища.

Друга група. Дослідження присвячені характеристикам поведінки медичного персоналу в різних професійних ситуаціях при спілкуванні з пацієнтом та між колегами.

Американський лінгвіст Хаймсон Д. [17] один 3 перших вжив термін - комунікативна компетентність він вважає, що це здатність людини використовувати мову в мінливих соціальних умовах - гнучко, точно та швидко. Тобто людина як срахівець повинна знати і вміти користуватися мовою залежно від соціальних обставин, соціокультурного середовища.

Третя група. Вченими проаналізовані умови та розроблені методи, методики та управління процесом фрормування комунікативної компетенції в умовах медичного коледжу та умовах професійної діяльності (рис. 2). Важливим аспектом професійного розвитку медичної сестри $€$ безперервне навчання [18], а постійне оновлення знань та навичок i застосування їх на практиці це не тільки реалії сучасних вимог до профресії але і потреби самовдосконалення. Сукупність вище переліченого $€$ запорукою професійного росту та підвищення якості медичної допомоги. На жаль, зміни в системі підвищення кваліфрікації медичних працівників запроваджені у
2018 році [19] їх не торкнулися. Тому, на сьогодні стає дуже актуальним питанням для керівного складу лікувально-профрілактичного закладу пошук та впровадження ефрективних методів навчання медичних сестер без відриву від виробництва теми тренінгів та семінарів можуть бути наступними:

- Як врятуватися від профресійного емоційного вигорання та зміцнення волі;

- Правила побудови безконсрліктного діалогу з пацієнтом;

- Принципи безконфрліктного спілкування медичної сестри з колегами;

- Протистояння почуттю розчарування, невпевненості в собі та провини;

- Самоконтроль при підвищеній дратівливості тощо.

Процес формування комунікативної компетенції та управління їм можна поділити на два етапу:

I етап відбувається в коледжі де за допомогою лекції, практичних занять та тренінгів з дисциплін загального циклу у студентів розвиваються комунікативні навички. На заняттях дисциплін практичної спрямованості студенти вивчають особливості спілкування 3 пацієнтами різного профрілю, а під час проходження виробничої практики застосовують ці знання за допомогою проходження тренінгів для середнього медичного персоналу у лікувально-профрілактичному закладі закріплюють їх та можуть застосовувати на практиці.

II етап - етап просресійної спрямованості де середній медичний персонал лікувальнопрофрілактичного закладу навчають, удосконалюють або корегують комунікативні 


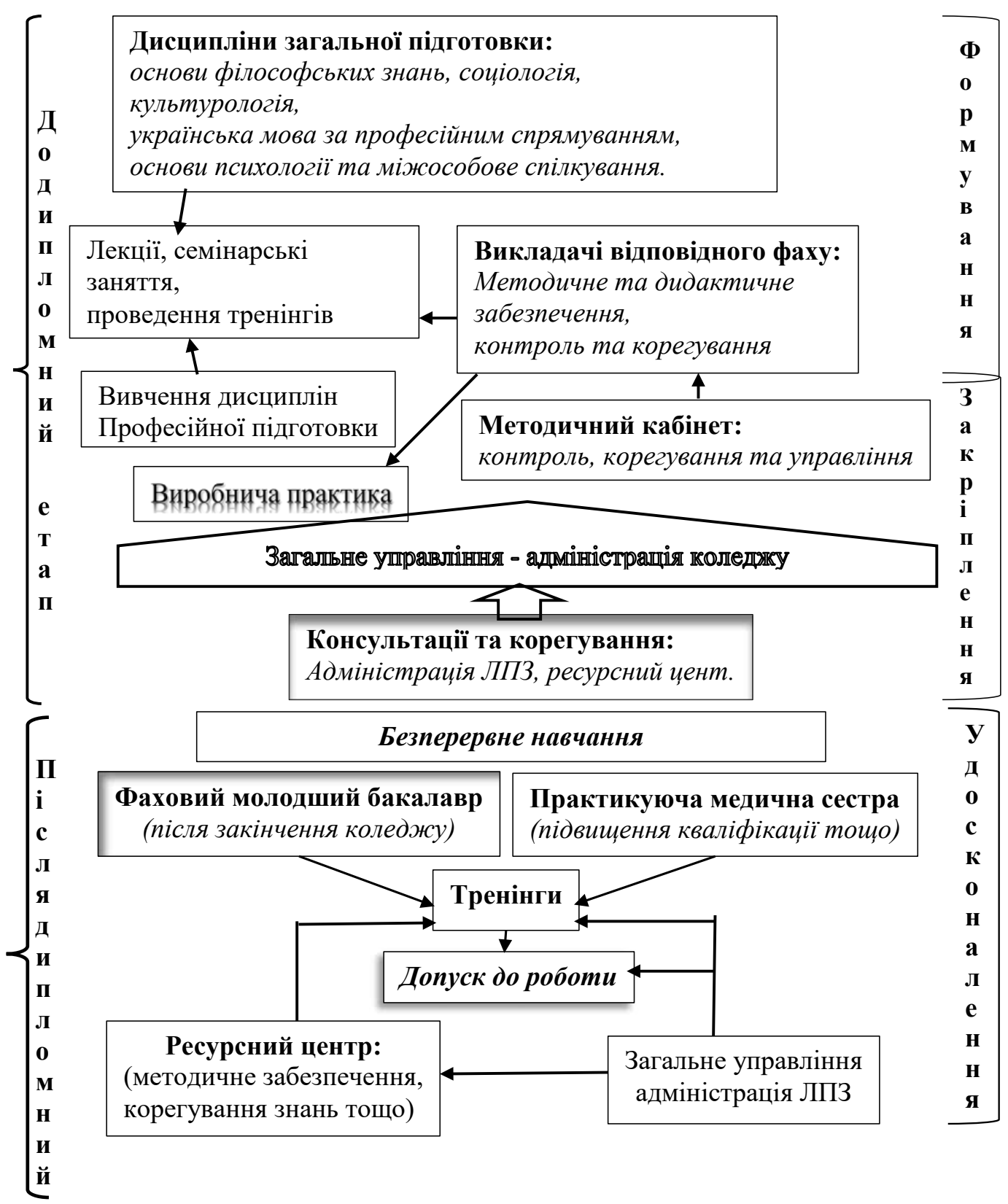

Рис. 2. Загальна модель формування та управління комунікативною компетенцією

Джерело: розроблено автором на підставі [10; 12]

навички. Важливо підкреслити, що молодий спеціаліст немаючі практичного стажу роботи може володіти знаннями, навичками - комунікативної компетенції, але вона сорормована загально. Тому при прийомі на роботу молодого спеціаліста важливо оцінити його знання та вміння і при необхідності скорегувати їх після чого можна допустити до роботи. Подальше в рамках безперервного розвитку середнього медичного персоналу комунікативна компетенція удосконалюється, корегується за допомогою тренінгів та практичних семінарів, а оцінку стану цієї компетенції про- водять за допомогою тестування. Методичне забезпечення тренінгів, семінарів та оцінка стану комунікативної компетенції лежить на ресурсному центрі. Постійно на усіх етапах їде управління процесом формування компетенції, яким керує адміністрація закладу.

Висновки 3 цього дослідження і перспективи подальших розвідок у даному напрямку. Дані дослідження сприяють глибшому й повнішому розумінню ролі комунікативної компетенції в професійній діяльності середнього медичного персоналу. Розробка та впровадження методів навчання та удо- 
сконалення комунікативних навичок дозволяє медичній сестрі самовдосконалюватися, а методи управління цими процесами дозволяють своєчасно корегувати їх. Комунікативні навички середнього медичного персоналу в час медичних ресорм та стрімкого розвитку приватної медицини, це запорука успіш- ного лікування, підвищення якості медичного обслуговування. Перспективи подальшого дослідження полягає в розробці педагогічних методів підвищення квалісрікації середнього персоналу без відриву від основної діяльності та методів управління цими процесами як на місцевому рівні так і на рівні держави.

\section{СПИСОК ВИКОРИСТАНИХ ДЖЕРЕЛ:}

1. Salmon P., Mendick N., Young B. Integrative qualitative communication analysis of consultation and patient and practitioners' perspectives: towards a theory of authentic caring in clinical relationships. Patient Education and Counselling. 2011. Vol. 82. № 3. P. 448-454.

2. Демянчук М.Р. Практика фрормування культури професійного спілкування майбутніх фрахівців медицини. Педагогіка фоормування творчої особистості у вищій і загальноосвітній школах. 2016. Вип. 51. С. 129-137.

3. Зозуля А.І. Медико-соціальне обґрунтування якісно нової системи спеціалізованої допомоги хворим 3 судинною патологією головного мозку : дис. ... д. мед. н. : 14.02.03. Київ, 2014. 40 с.

4. Горачук В.В. Медико-соціальне обґрунтування моделі системи управління якістю медичної допомоги : дис. ... д. мед. н. : 14.02.03. Київ, 2015. 36 с.

5. Загородній С.М. Медико-соціальне обґрунтування системи збереження психічного здоров'я сільського населення : дис. ... к. мед. н. : 14.02.03. Київ, 2011. 24 с.

6. Золотарьова Ж.М. Обґрунтування моделі удосконалення підготовки та підвищення кваліфікації медичного персоналу для надання паліативної допомоги : дис. ... к. мед. н. : 14.02.03. Івано-Франківськ, 2015. 26 с.

7. Яворський А.М. Медико-соціальне обґрунтування удосконаленої пацієнтоорієнтованої системи управління якістю медичного обслуговування (на прикладі стаціонарної хірургічної допомоги) : дис. ... к. мед. н. : 14.02.03. Київ, 2014. 23 с.

8. Мединська А.В., Коноваленко С.О. Професійність медичної сестри у спілкуванні $з$ пацієнтами. Медсестринство. 2016. № 3. С. 7-13.

9. Hromtseva D.K., Krupskyi O.P. Professional culture and security: an innovative approach to implementing a medical facility. European Journal of Management Issues. 2015. № 5. P. 15-23.

10. Самборська Н.М. Формування соціально-комунікативної компетентності майбутніх фрахівців зі спеціальності «медсестринство» у процесі вивчення гуманітарних дисциплін : дис. ... к. пед. н. : 13.00.04. Житомир, 2018. 22 c.

11. Stryukov V., Hromtseva O. Analysis of key competences in vocational education. Journal of Scientific Papers «Social Development and Security». 2019. № 9(5). P. 94. doi: org/10.33445/sds.2019.9.5.6

12. Знаменська М.А., Слабкий Г.О., Знаменська Т.К. Комунікації в охороні здоров'я : монограсрія. Київ, 2019. 194 с.

13. Сидоренко О. Інформаційні ресурси як об'єкт інформаційних правовідносин. Підприємництво, господарство і право. 2018. № 4. С. 173- 182.

14.Про інформацію : Закон України від 2 жовтня 1992 року № 2657-XII / Верховна Рада України. URL: https://zakon.rada.gov.ua/laws/show/2657-12\#Text (дата звернення: 16.12.2020).

15. Мединська А.В., Коноваленко С.О. Професійність медичної сестри у спілкуванні з пацієнтами. Медсестринство. 2016. № 3. С. 7-13.

16. Литвинова А.Е. Формування компетентності медичних сестер. Медсестринство. 2017. № 4. С. 16-18.

17. Hais D.G. How many levels should a grammar recognize? Language and discourse: Rest and Protest. Amsterdam, Philadelphia, 2006. P. 12.

18. Кадрові ресурси системи охорони здоров'я в Україні. Ситуаційний аналіз. Проект USAID «Підтримка реформи охорони здоров'я» / наук. ред. Ю. Середа. Київ, 2019. 133 с.

19.Про затвердження Положення про систему безперервного професійного розвитку фахівців у сфері охорони здоров'я : Постанова КМ України від 28 березня 2018 р. № 302. URL: https://zakon.rada.gov.ua/laws/ show/302-2018-\%D0\%BF\#Text (дата звернення: 18.12.2020).

\section{REFERENCES:}

1. Salmon P., Mendick N., \& Young B. (2011) Integrative qualitative communication analysis of consultation and patient and practitioners perspectives: towards a theory of authentic caring in clinical relationships. Patient Education Counselling, vol. 82, no. 3, pp 448-454. 
2. Demianchuk M.R. (2016) Praktyka formuvannia kultury profesiinoho spilkuvannia maibutnikh fakhivtsiv medytsyny [The practice of forming a culture of professional communication of future medical professionals]. Pedagogy of formation of creative personality in higher and general education schools, vol. 51, pp. 129-137.

3. Zozulia A.I. (2014) Medyko-sotsialne obgruntuvannia yakisno novoi systemy spetsializovanoi dopomohy khvorym z sudynnoiu patolohiieiu holovnoho mozku [Medical-social substantiation of a qualitatively new system of specialized care for patients with vascular pathology of the brain] (Doctor's Thesis), Kyiv: Shupyk National Medical Academy of Postgraduate Education.

4. Horachuk V.V. (2015) Medyko-sotsialne obgruntuvannia modeli systemy upravlinnia yakistiu medychnoi dopomohy [Medical-social substantiation of the model of health care quality management system] (PhD Thesis), Kyiv: Shupyk National Medical Academy of Postgraduate Education.

5. Zahorodnii S.M. (2011) Medyko-sotsialne obgruntuvannia systemy zberezhennia psykhichnoho zdorovia silskoho naselennia [Medical-social substantiation of the system of mental health of the rural population] (PhD Thesis), Kyiv: Shupyk National Medical Academy of Postgraduate Education.

6. Zolotarova Zh.M. (2015) Obgruntuvannia modeli udoskonalennia pidhotovky ta pidvyshchennia kvalifikatsii medychnoho personalu dlia nadannia paliatyvnoi dopomohy [Substantiation of model of medical personnel's advanced training improvement for palliative care] (PhD Thesis), Ivano Frankivsk: Ivano Frankivsk National Medical University.

7. Yavorskyi A.M. (2014) Medyko-sotsialne obgruntuvannia udoskonalenoi patsiientooriientovanoi systemy upravlinnia yakistiu medychnoho obsluhovuvannia (na prykladi statsionarnoi khirurhichnoi dopomohy) [Medical-social substantiation of the improved patient-oriented system of quality management of medical care (on the example of inpatient surgical care)] (PhD Thesis), Kyiv: Shupyk National Medical Academy of Postgraduate Education.

8. Medynska A.V., Konovalenko S.O. (2016) Profesiinist medychnoi sestry u spilkuvanni z patsiientamy [Professionalism of the nurse in communication with patients]. Nursing, no. 3, pp. 7-13.

9. Hromtseva D.K., Krupskyi O.P. Professional culture and security: an innovative approach to implementing a medical facility. European Journal of Management Issues, no. 5, pp. 15-23.

10. Samborska N.M. (2018) Formuvannia sotsialno-komunikatyvnoi kompetentnosti maibutnikh fakhivtsiv zi spetsialnosti «medsestrynstvo» u protsesi vyvchennia humanitarnykh dystsyplin [Formation of social and communicative competence of future specialists in the specialty "nursing" in the process of studying the humanities] (PhD Thesis), Zhytomyr: Zhytomyr Ivan Franko State University.

11.Stryukov V., Hromtseva O. (2019) Analysis of key competences in vocational education. Journal of Scientific Papers «Social Development and Security, no. 9(5), p. 94. doi: https://doi.org/10.33445/sds.2019.9.5.6

12.Znamenska M.A., Slabkyi H.O., \& Znamenska T.K. (2019) Komunikatsii v okhoroni zdorovia [Health communications]: Monographs. Kyiv, p. 194.

13. Sydorenko O. (2018) Informatsiini resursy yak obiekt informatsiinykh pravovidnosyn [Information resources as an object of information relations]. Entrepreneurship, economy and law, no. 4, pp. 173-182.

14.Pro informatsiiu: Zakon Ukrainy vid 2 zhovtnia 1992 roku № 2657-XII / Verkhovna Rada Ukrainy [Based on: Law of Ukraine of October 2, 1992 № 2657-XII / Verkhovna Rada of Ukraine]. URL: https://zakon.rada.gov.ua/laws/ show/2657-12\#Text

15. Medynska, A.V., \& Konovalenko, S.O (2016) Profesiinist medychnoi sestry u spilkuvanni z patsiientamy [The professionalism of the nurse in communicating with patients]. Nursing, no. 3, pp. 7-13.

16. Lytvynova A.E. (2017) Formuvannia kompetentnosti medychnykh sester [Formation of nurses' competence]. Nursing, no. 4, pp. 16-18.

17. Hais D.G. (2006) How many levels should a grammar recognize? Language and discourse: Rest and Protest. Amsterdam, Philadelphia, p. 12.

18. Sereda Yu. (Ed) (2019) Kadrovi resursy systemy okhorony zdorovia v Ukraini. Sytuatsiinyi analiz [Human resources of the health care system in Ukraine. Situational analysis]. Kyiv: USAID Health Care Reform Support Project. (in Ukrainian)

19. Pro zatverdzhennia Polozhennia pro systemu bezperervnoho profesiinoho rozvytku fakhivtsiv u sferi okhorony zdorovia: Postanova KM Ukrainy vid 28 bereznia 2018 r. № 302 [On approval of the Regulations on the system of continuous professional development of specialists in the field of health care: Resolution of the Cabinet of Ministers of Ukraine]. URL: https://zakon.rada.gov.ua/laws/show/302-2018-\%D0\%BF\#Text 